\title{
Evaluating Platform Openness in Logistics based on a Taxonomic Analysis
}

\author{
Estelle Duparc \\ TU Dortmund University \\ Estelle.Duparc@tu-dortmund.de \\ Carina Culotta \\ Fraunhofer IML \\ Carina.Culotta@iml.fraunhofer.de
}

\author{
Boris Otto \\ TU Dortmund University \\ Fraunhofer ISST \\ Boris.Otto@tu-dortmund.de \\ Boris.Otto@isst.fraunhofer.de
}

\begin{abstract}
Digital platforms are becoming increasingly important in logistics to enhance business models and ensure competitiveness. As new players enter from the $B 2 C$ sector, the need to innovate is intensifying for traditional firms. To compensate for disadvantages, such as missing platform knowledge or a late entrance, open strategies, e.g., shared governance or open source, can spur platform development and establishment. The resulting open platform ecosystems are a promising approach in entering the platform business for struggling firms. As first initiatives aim to promote open logistics ecosystems, our research objective is to evaluate the current state of openness regarding logistics platforms. We use a taxonomy to identify relevant design elements from a business model's perspective. Building on the taxonomic analysis, we evaluate relevant openness dimensions to display the current state of openness in logistics platform ecosystems. We conclude by giving an outlook on future research avenues by providing potential research questions.
\end{abstract}

\section{Introduction}

Continuous digitalization is forcing multiple industries into a more competitive and dynamic market environment [1]. Diverse experiences across industries (e.g. transportation, hospitality) show that digital disruption changes markets within a short period of time: Established firms that have been dominant for decades are losing their market leadership to firms embracing platform-based strategies [2,3]. According to current studies, more than $30 \%$ of all global revenues (\$60 trillion) could be generated by platform-based ecosystems until 2025 [4]. However, not all industries are currently benefiting from the platform business to the same extend. The most prominent success stories, for example, Apple, Microsoft, Amazon, or Facebook, originates from the $\mathrm{B} 2 \mathrm{C}$ or $\mathrm{C} 2 \mathrm{C}$ context [5]. In the $\mathrm{B} 2 \mathrm{~B}$ sector, only $3 \%$ of established firms are estimated to have adopted an effective platform strategy, even though the industry is considered a lucrative market for establishing profitable B2B platforms [6].

While traditional firms struggle to occupy existing white spots in the industry, experienced platform businesses from the B2C market and new start-ups start to enter the $\mathrm{B} 2 \mathrm{~B}$ market $[2,7]$. The phenomenon is visible in the logistics industry: Platform firms like Uber Freight rush into the logistics sector by offering onlinebased logistics solutions [2]. Simultaneously, specialized start-ups called "Logistics Tech" combining the knowledge of traditional logistics and digital platform businesses have begun to disrupt the logistics sector. The new players offer logistics and additional services via digital platforms that match supply and demand in different branches to increase resource efficiency $[7,8]$.

However, traditional companies can use strategies based on open concepts (open strategies) to catch up with their platform competitors. Open strategies are used to increase the platform's openness for achieving a critical mass of participants faster than other platform ecosystems $[9,10]$. For example, open strategies are applied to accelerate the growths of technological platform ecosystems by allowing third-party developers to contribute to the value creation process [11]. Also, from an organizational perspective, open approaches can foster growth by allowing new complementor sides to join the platform [12]. New open approaches propose a shared platform development to minimize risks and combine resources [13, 14]. Those resulting open platform ecosystems are relatively new and underrepresented in literature but hold promising approaches in entering the platform business for struggling companies $[13,15]$.

While general platform characteristics are a vital topic in research, the development of open platform ecosystems is underrepresented. However, in practice, open platforms seem to be a promising approach as traditional firms often lack resources to create vital platform ecosystems $[13,15,16]$. For example, two 
initiatives in the logistics sector, the Silicon Economy ${ }^{1}$ and the FEDeRATED project ${ }^{2}$, promote the establishment of open logistics ecosystems in Europe. Considering the practical relevance and the existence of enough logistics platforms as an empirical database, we start to evaluate openness in the logistics sector. In research, first papers have begun to analyze digital business models in logistics by using taxonomies to entangle underlying design elements $[17,18]$. Taxonomies assist researchers in structuring complex domains based on the classification of objects and therefore play an important role in research and management [19]. In business model research, taxonomies are widely used artifacts as they support researches to decompose the complex concepts of business models [20]. Therefore, we consider taxonomic analysis from a business model's perspective as appropriate research method to build upon prior research and deepen current findings. For the reasons outlined above, the first research question is as follows:

Research Question 1 (RQ1): What are conceptually and empirically grounded design dimensions and characteristics of platform business models in logistics?

As mentioned earlier, platform openness can spur the development of vital platform ecosystems [10,11]. However, open platform ecosystems, e.g., open-source ecosystems, in logistics have not been analyzed yet. Therefore, we draw from our first findings to display the actual degree of platform openness in the logistics domain. Our second question reads:

Research Question 2 (RQ2): What is the current state of open platform ecosystems in logistics?

The paper is structured as follows. After the introduction, we illustrate the theoretical background consisting of digital platform ecosystems and business model theory. Then, we explain our research approach, including the data collection and the taxonomy development method. After that, we present the development iterations and our final taxonomy including, its dimensions and characteristics. Next, we evaluate and discuss the openness of logistics platform ecosystems. In the last section, we explain the contributions of our findings and their limitations. Finally, we finish with an outlook on possible research avenues.

\section{Theoretical Background}

\subsection{Digital Platform Ecosystems}

Digital platforms capture, transfer, and monetize data over a digital infrastructure and can include physical elements such as product offerings [21, 22]. They provide the foundation upon which outside firms can develop complementary offerings, such as products, technologies, or services, and create the basis for bringing together and orchestrating different actors, e.g., consumers and producers [23]. Prior research on digital platform concepts can be divided into two types: The platform as a market-oriented vehicle for processing transactions, described as transaction platform, and the platform as a technological infrastructure, known as an innovation platform [5, 24]. Non-technological definitions describe platforms as commercial networks or marketplaces for mediating transactions via technological interfaces [22, 25]. Technological-based definitions see the platform as a technological infrastructure that is modularly expandable and can be continuously developed. External developers can contribute by providing complements, e.g., apps or complementary services, to the platform [26].

The resulting network of interacting parties on the platform forms the ecosystem that is defined as "Collection of firms interacting with a contribution to the complements" [27, p. 4]. To understand the notion of open platform ecosystems, we introduce two dimensions that characterize a platform: the architecture and the governance [15]. The architecture describes the platform's modular system design in which specific components remain stable, while other components (e.g., complements or boundary resources) vary over time [28]. If larger parts of the architecture are open, these platforms are called open source platforms, e.g., Linux [29]. On an organizational level, governance refers to the control mechanisms, such as decision control, through which a platform owner exerts influence over the platform participants [21]. If the control mechanism allows influence from outside or the platform owner is represented by several entities, the platform is referred to as open platform [13, 22]. Thus, open platform ecosystems can be open regarding the architecture and/or the governance mode.

In platform ecosystems, value is created through the interaction between different groups or actors within one group of the platform [27]. Therefore, the platform's value increases with the number of participants in the ecosystem fueling the phenomenon known as "network effects" [30]. Network effects occur

\footnotetext{
${ }^{2}$ http://www.federatedplatforms.eu/
}

\footnotetext{
${ }^{1}$ https://www.silicon-economy.com/en/homepage/
} 
if the rising number of one user group increases the platform's attractiveness for its own or another present group, e.g., app stores that gain value with the number of users and developers [21]. Consequently, network effects are the foundation of successful platforms that profit from increasing returns to scale [21, 31]. Farreaching network effects are observed in two- or multisided platforms. Two-sided platforms bring together two market sides, e.g., consumers and software providers, whereas multi-sided platforms connect at least three parties, e.g., consumer, software providers, and hardware providers [32]. We exclude one-sided platforms, e.g., management software, from our analysis as the most powerful network-effects occurs in two- or multisided platforms [21].

\subsection{Platform Business Models}

Business models are a highly relevant analytical object in the field of Information Systems as they are used to analyze the complex modus operandi of how a business works, e.g., as a simplified ontological representation of designable business model elements [33]. They are used to describe how an organization creates, delivers, and captures value while generating revenue [33, 34]. The concept helps to construct management tools that are utilized to design and to understand the complex on-goings in a business (e.g., see [34]). However, no generally accepted definition of business models and their underlying elements has been established yet [35].

Nowadays, the notion of "digital" business models has risen in prominence, which describes business models that leverage, for example, underlying platform logics or data as a key resource [36]. Digital business models are an integral part of platforms. They answer the managerially important question on designing specific platform elements, such as the value proposition, the transaction partners, the revenue model, or the platform architecture [37, 38].

After [39], platforms are characterized by their business model's openness as they inherently rely on value co-creation from external actors to trigger network effects between the demand and supply side. Therefore, openness is a key success factor for platforms to accelerate growth, to enable third-party innovations and to trigger platform dynamics, such as monopolization known in the "winner-takes-it-all"-phenomenon $[9,10$, 39, 40]. Different aspects need to be addressed in platform business models to define platform openness: For example, the platform openness can vary through the architectural (open source) or the organizational openness [41, 42]. Also, a platform can vary in its openness towards supplier and user sides [43]. As the degree of openness strongly influences a platform business model, platform openness is a central aspect of our research.

\section{Research Design}

\subsection{Data Collection}

To build a corpus of relevant literature as basis for the taxonomy development, we draw from [44] and [45] to conduct a structured literature review. We looked for publications that focus on general and logistics-specific platform characteristics.

First, we chose the databases AISeL and Scopus as they cover the essential journals and conferences in Information Systems. We conducted a title and abstract search to ensure the relevance of the articles and enhanced the results with forward and backward search. Duplications, non-peer-reviewed articles as well as nonEnglish written literature were discarded during the search process. Additionally, we excluded articles that merely describe platform concepts and characteristics but focus on using platforms in specific domains.

Table 1: Structured literature review

\begin{tabular}{|l|c|c|}
\hline Search Strings & Hits & Included \\
\hline $\begin{array}{l}\text { "taxonomy" AND } \\
\text { "platform" }\end{array}$ & 79 & 16 \\
\hline $\begin{array}{l}\text { "logistics" AND } \\
\text { "platform" }\end{array}$ & 314 & 6 \\
\hline $\begin{array}{l}\text { Forward and backward } \\
\text { search }\end{array}$ & - & 5 \\
\hline
\end{tabular}

Next, to enhance the purely literature-based findings of the taxonomy with empirical data, we construct a database of logistics platforms by identifying suitable businesses through databases, such as AngelList (start-up database) [46], SourceForge (software database) [47], Capterra (software database) [48] and internet research. The final dataset consists of 80 samples that we divided into two sub-samples to enhance and validate the taxonomy itertively.

\subsection{Taxonomy Development}

Taxonomies are useful artifacts to structure a specific domain and are used as a tool to cluster objects into groups based on their similarities [49]. In business model research, taxonomies are a widespread method to understand business model concepts by shedding light on their specific building blocks and structures [17, 36, 38]. 
Our research approach follows the method of [19] for taxonomy development. The method is widely used in the field of Information Systems and is the de facto standard for taxonomy design [50]. The method consists of seven steps integrating two paradigms, e.g., an inductive and a deductive approach, that are iteratively combined until the design of the taxonomy reaches theoretical saturation[19, 51].

First, researchers must define a meta-characteristic, that reflects the overall purpose of the taxonomy and which is the source from which all subsequent steps are derived. As the method is iterative, the next step is to define ending conditions whose fulfillment terminates the method execution. We draw from [19] and employ subjective and objective ending conditions.

The methodological core of the method is the dichotomous division of the taxonomy generation. Firstly, researchers may apply a conceptual-to-empirical approach, which begins using conceptually derived dimensions that are then tested empirically against a sample of objects. Alternatively, one can use the empirical-to-conceptual approach, which prescribes the inductive generation of dimensions, which are then conceptualized. That process is repeated until the ending conditions are met [19].

\section{Final Taxonomy}

\subsection{Taxonomy Development Procedure}

This paper develops a taxonomy of design elements for platforms from a business model's perspective in logistics using scientific and empirical data. The dichotomous approach ensures a systematic representation of the current domain that covers theory as well as practice. Following [19], we define a metacharacteristic for the present taxonomy that reads as follows: "Key Elements of Platform Business Models in Logistics”, which reflects RQ1. Next, we use objective and subjective ending conditions, which determine the end of the development process that we draw from [19]. As a starting point, we choose a conceptual-to-empirical approach to define a theoretical framework represented by meta-dimensions. The findings from the first iteration are enriched by empirical-to-conceptual in two following iterations that cover a dataset of 80 firms. Next, a description of the procedure is given below.

$1^{\text {st }}$ Iteration (Conceptual-To-Empirical). First, to suitably relate to the existing knowledge base, we conduct a structured literature review. The review is used to identify existing work thematizing platform taxonomies and specific characteristics of logistics platforms. To systemize our findings, we used a concept-matrix approach, as recommended by [44]. As the literature on logistics platform concepts is sparse (see [17, 18]), we derive general dimensions and characteristics of the taxonomy following the metadimensions of [43]:

- Value Creation

- Platform Architecture

- Actor Ecosystem

The Value Creation describes the firm's ability to offer a product or service, how it is created and how value is captured [52]. After the first iteration, the metadimension included the dimensions Key Offering, Modality, and Revenue Model [18]. The second metadimension, the Platform Architecture, thematizes the fundamental organizational layout of the platform, including different aspects of openness [43]. The next meta-dimension Actor Ecosystem portrays the Platform Owner, the Actor Types, and the Geographic Scope.

$2^{\text {nd }}$ Iteration (Empirical-To-Conceptual). In the second iteration, we use an empirical-to-conceptual approach to validate the conceptual framework and add logistics specific dimensions and characteristics to the taxonomy. For this purpose, we use the first dataset of our database consisting of 40 logistics platforms. Using public data is a common practice in digital business model research (e.g., see $[18,36]$ ). Usually, the underlying argumentation is the high degree of transparency in business models [53]. To ensure that we only consider relevant firms in our samples, we use the following two criteria: First, we searched for a logisticsrelated offering, such as transportation or warehousing. Second, we excluded firms that did not bring at least two market sides together. Then we classified the first 40 samples into the taxonomy and reviewed the ending conditions following [19]. As new dimensions, such as Physical Resource, Customer Openness, and the Complementor Openness, evolved, we conducted a third iteration.

$3^{\text {rd }}$ Iteration (Empirical-To-Conceptual). The third iteration considers the other 40 examples. During the iteration, we tested dimensions and characteristics for robustness by checking the fulfillment of the objective and subjective ending conditions after [19]. The classification of the remaining firms did not lead to further modifications of the dimensions or characteristics of the taxonomy. No changes were made, 
so we opted to finish the taxonomy development procedure.

\subsection{Taxonomy}

The following section presents the final taxonomy consisting of 14 dimensions and 59 characteristics (see Table 1). The method of [19] assumes mutually exclusive characteristics. However, our taxonomy allows non-exclusive characteristics that align with previous research as "the creation of exclusivity through additional generalization and linguistic adaptation somewhat complicates the result" [18, p. 5382, 54]. The exclusivity is specified in the last column of Table 1. In terms of visualization, we chose a morphology as it has a high merit in describing morphological, designable components of an artifact and therefore suits to visualize taxonomies [55]. Following, the taxonomy's metadimensions, including its dimensions and characteristics, are described.

\subsection{Value Creation}

The value creation explains the platform business model's logic, such as the value proposition, key resources, or the monetarization strategy $[43,52]$. The Key Offering (1) reflects the five tasks of logistics described by [56]: Storage, warehousing and material handling, packaging and unitization, inventory, freight transport, and information and control. The first characteristic that we summarized as warehousing describes the provision and management of warehouses and the organization of storage, the structuring of goods, and the movement of related short-distance materials. The next characteristic, packaging, thematizes the preparation of a good for transport, e.g., labeling and packaging. Next comes the inventory that treats the stock of products to ensure optimal processes. The transportation characteristic describes all services related to the transportation of goods from a location to another one. Lastly, information and control tasks deal with all activities around optimizing the supply chain and logistics processes through digital services, such as management software, data analytics or tracking services [56]. As most platforms included a transportation service, we consider the Modality (2) as a relevant dimension, which describes the transportation mode of a good, e.g., road, sea, multimodal, or in case of digital services, independent [18]. The platform's Physical Resource (3) can either be provided by the platform (own resource) or by external contributors (external resource). Regarding the Revenue Model (4), we draw from previous business model taxonomies (see [17], [18], and [38]) to describe a specific pattern of revenue generation, e.g., through commissions, subscription, customized prices, service fees or pay-peruse.

\subsection{Platform Architecture}

Regarding the platform architecture, fundamental questions of the platform design, e.g., the Platform Type (5) or the addressed Platform Sides (6), need to be considered. Similar to [17] we found digital marketplaces/brokerages and booking platforms to be relevant characteristics during the empirical phase. Marketplaces/brokerages and booking platforms differ in terms of their intermediary role: While marketplaces and brokerages directly matches the demand side with specific offers, booking platforms solely displays all offers from which the demand side can choose. However, as we exclude one-sided platforms, we did not find purely digital service platforms or SaaS-platforms that were two- or multi-sided. Instead, we complement the dimension Platform Type (5) with integration services that bring together different platforms to cover several logistics services and innovation platforms that provide technological infrastructure for third-party innovations (e.g., app stores). We focus on two- and multi-sided platforms that are characterized by the Platform Sides (6).

Our second research questions aim to analyze the current state of open platform ecosystems in logistics. This meta-dimension focusses on different openness aspects drawing from [43]. First, a firm can decide to open the platform architecture through the Platform Access (7), e.g., the platform core or specific product features to benefit from open-source potentials, such as improved code quality or open innovation $[57,58]$. We differentiate between closed source, open-source APIs, open-source projects, and open source. In our analyzed cases, the open-source APIs did not serve as boundary resources to modify code but to enable data exchange and quicker integration. Only with the provision of open-source projects, (small) parts of the platform were provided open source. On an organizational level, openness refers to the Decision Control (8) given to complementors, e.g., decisions regarding the future orientation of the platform $[13,41]$. The decisions are either keystone-driven, consortium-driven or peer-topeer-driven. The Customer Openness (9) treats the platform's openness towards customers. Logistics platforms are either fully open; everyone can access the offering, or they have conditions for access, e.g., just industrial customers can see the offering. The characteristics describing the Complementor Openness (10) are similar to those of the customers' dimension except for the option to restrict the access to 
selected partners. A high openness towards suppliers leads to a higher number of complementary offers, whereas a restricted openness for selected partners increases the overall quality of complements [59].

\subsection{Actor Ecosystem}

The next meta-dimension treats the participants that form the platform ecosystems [43]. The Platform Owner (11) is the lead organization responsible for the platform sometimes referred to as the ecosystem's keystone organization [21]. Regarding logistics platforms, we found that he can be represented by a single firm (e.g., Start-up, small or medium-sized enterprise, or large enterprise) or by the shared entity, for example, as a consortium. The analyzed samples show that the Owner Background (12) of logistics platforms originates from logistics, commerce, IT, or mixed sectors. A special characteristic is the logistics tech that represents IT firms solely focusing on the logistics sector. In contrast to the traditional logistics firms, they do not provide physical services. The next category treats the ecosystem's Actor Types (13). As most analyzed logistics platforms focus on transportation services, the shipper and the carrier represent typical actors in a logistics ecosystem. Next, the broker represents an intermediary instance to mediate logistics services to customers that do not directly access the platform. Further actor types originate from logistics-related sectors, such as manufacturer or dealer. Some platforms allow consumers to use or extend the platform offers. Lastly, we summarize unusual actor types in the characteristic other. The last dimension describes the platform ecosystem's Geographic Scope (14). For example, a key offering can be available in a city (local), in a country (national), on a continental (continental) or worldwide (global/independent).

Table 2: Taxonomy of platform business models in logistics. $E=$ Exclusivity, $Y=Y e s$, and $N=$ No

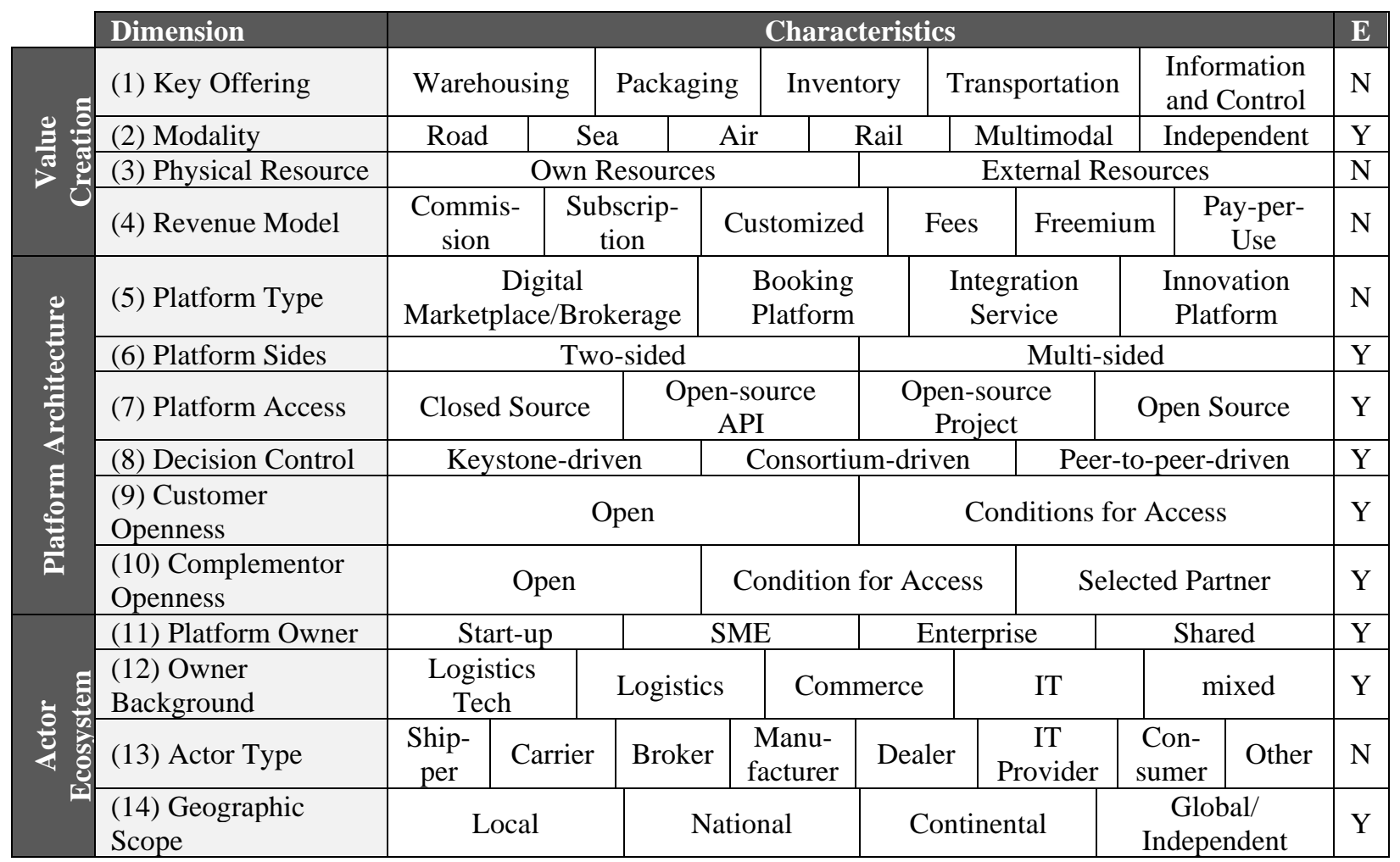




\section{Openness in Logistics Platforms}

With the 80 analyzed logistics platforms, which were used during the creation and evaluation of the taxonomy, it is possible to answer RQ2: Evaluating the actual state of open ecosystems in logistics. For this purpose, we analyze the relevant openness dimensions Platform Access, Decision Control, Customer Openness, and Complementor Openness. As those dimensions are mutually exclusive, a precise percentage distribution can display the actual degree of openness in logistics platform ecosystems. Evaluating the four categories give a holistic and up-to-date look at open platform ecosystems in logistics.

The Platform Access is relevant to analyze the platform openness on an architectural level. Based on the platform access, we explore the existence of opensource platforms in logistics. As Figure 1 shows, almost $60 \%$ of the logistics platforms are closed source, meaning that no external modifications can be made to the platform's underlying code. $32 \%$ of the logistics platforms use open-source APIs to enable data exchange and interoperability. Solely $6 \%$ of the analyzed platforms have open-source projects beyond opensource APIs and allow external developers to participate. No open-source platform, like Google's Android platform, was found within the samples. The evaluation of the platform access shows that most logistics platforms are somewhat restrictive than open. If openness is allowed, it is often limited to open-source APIs to enable quicker integration. The open-source potentials, e.g., open innovation, are not yet used in logistics platform ecosystems. Therefore, we identify a research avenue regarding the reasons for logistics platforms' closedness on architectural level.
Next, we analyze the organizational openness level evaluating the Decision Control. As seen in Figure 1, almost all logistics platforms (96\%) are keystone-driven meaning that the decision control remains in one firm. The remaining logistics platforms are consortiumdriven and distribute the decision control on several firms, e.g., in form of a managerial board. Peer-to-peerdriven approaches seem not relevant in logistics platforms. This can be explained by the fact that peerto-peer-driven projects often emerge in non-profit communities rather than in for-profit organizations [41]. Also, on an organizational level, most logistics platforms are rather restrictive than open. Therefore, we propose another research avenue that investigate open governance models in logistics platforms.

Most logistics platforms (75\%) restrict the Customer Openness of their ecosystem and do not publicly display their offering. One explanation for this is that firms must balance the trade-offs between full openness (less direct control), e.g., direct access to the product offer and their providers, and reduced openness to increasing value capture, e.g., transaction fees [59]. Further research could focus on analyzing the transfer of $\mathrm{B} 2 \mathrm{C}$ business models to the $\mathrm{B} 2 \mathrm{~B}$ sector to promote openness on the customer level.

Lastly, we evaluate the Complementor Openness in logistics platform ecosystems. $6 \%$ can directly place their offer on the logistics platform. However, most platforms choose to restrict the access by either setting minor restrictions, such as the need for a VAT ID, or the selection of partners. Regarding the complementor openness, logistics platforms pursue common strategies observed in platform ecosystems [59]. However, the complementary offering is limited to physical services in most cases.

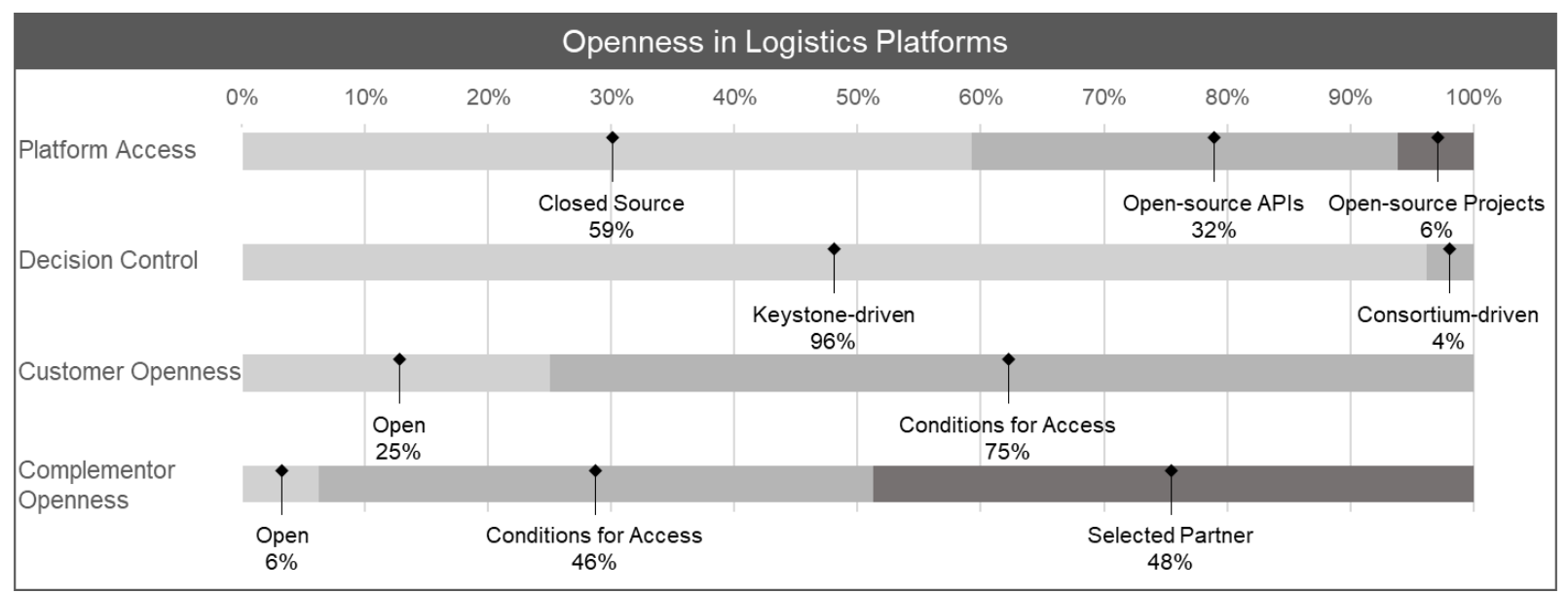

Figure 1: Evaluation of platform openness in logistics 
Overall, logistics platform ecosystems do not show a high degree of openness regarding the architectural and organizational levels. Open-source business models, such as open core platforms (e.g., Docker or Elastic) and open marketplaces (e.g., Android), or open-source platforms were not identified. Logistics platforms that allow openness mostly provide open-source APIs, which do not provide access to modify the platform but only a connection for integration. On an organizational level, most platforms are keystone-driven. However, recent trends in industry and research show the relevance of consortium-driven approaches [15]. On the customer and complementor levels, the openness degrees resemble strategies known from the literature [59].

\section{Conclusion, Limitations, and Outlook}

Our research gives an up-to-date look at the openness of logistics platform ecosystems from a business model's perspective. As preliminary work for the evaluation, we use a taxonomic analysis to provide a holistic view of logistics platforms, focusing on their value creation, platform architecture, and actor ecosystem.

However, our results are subject to research limitations. First, the taxonomy has typical limitations due to the subjective nature of the development process. For example, the authors of this paper identified relevant dimensions and characteristics. Other might consider different elements as more important. As we conducted desk research, we relied on publicly available data limiting our results on published material. Regarding the evaluation of openness in logistics ecosystems, we only focus on a limited number of dimensions. Therefore, a further analysis based on the taxonomy could focus on analyzing correlations between the openness dimensions and other dimensions (e.g., key offering, owner background etc.). In addition, the evaluation is restricted to provide a snapshot of current logistics platforms so that a longitudinal study would be useful to gain insights into the development of openness in logistics platform ecosystems.

Our paper provides several contributions. In terms of managerial contributions, our taxonomy assists practitioners in designing logistics platforms based on business model elements. By building upon existing taxonomies that focus on different research areas in the B2B sector and including empirical data, we create a logistics-specific taxonomy that eases the understanding of logistics platforms. We also provide an up-to-date snapshot of existing logistics platforms that can support the understanding of traditional firms on innovative business models. Further, practitioners can use the taxonomy to map existing platforms in order to entangle underlying structures that can be used for comparing or creating platforms. The evaluation of platform openness provides a holistic view of the entire sector and enables practitioners to take action regarding open platform ecosystems in logistics. Practitioners could use the evaluation as starting point to analyze success factors in the context of platform openness. The openness evaluation could also inspire practitioners to create innovative and open platform ecosystems that stand out from existing closed platforms.

Regarding scientific contributions, the paper develops a taxonomy that helps researchers to understand B2B platforms in logistics. The taxonomy provides an up-to-date look into logistics platforms and their business models by drawing from conceptual to empirical findings. Researchers can use the taxonomy as starting point to conduct a cluster analysis to identify archetypes of logistics platforms. Looking at the openness evaluation in logistics, the percentage distribution displays different dimensions of openness in logistics platform ecosystems. However, more research needs to be conducted to unveil barriers and potentials in open logistics platform ecosystems so that we lay the foundation for further research. Building on our findings, we recommend, among others, the following research avenues:

- Why are logistics platforms less open than other platforms (e.g., innovation platforms in the $\mathrm{B} 2 \mathrm{C}$ market)?

- Which open-source potentials could be beneficial for logistics platforms?

- How could (open source) B2C business models be transferred to the $\mathrm{B} 2 \mathrm{~B}$ sector to promote openness?

- Which correlations can be identified between the openness dimensions and the other dimensions of the taxonomy?

- How could open platform ecosystems in logistics be promoted?

- What types of logistics platforms are eligible for open platform ecosystems?

- Which organizational structures (e.g., consortium-driven) are suitable for open platform ecosystems in logistics?

\section{Acknowledgment}

This research was supported by the "Silicon Economy Logistics Ecosystem" funded by the Federal Ministry of Transport and Digital Infrastructure. 


\section{References}

[1] Hein, A., M. Schreieck, T. Riasanow, D.S. Setzke, M. Wiesche, M. Böhm, and H. Krcmar, "Digital platform ecosystems", Electronic Markets, 30(1), 2020, pp. 8798.

[2] Hofmann, E. and F. Osterwalder, "Third-Party Logistics Providers in the Digital Age: Towards a New Competitive Arena?", Logistics, 1(2), 2017, p. 9.

[3] Osterwalder, A., THE BUSINESS MODEL ONTOLOGY: A PROPOSITION IN A DESIGN SCIENCE APPROACH, Lausanne, France, 2004.

[4] Catlin, T., J. Lorenz, J. Nandan, S. Sharma, and A. Waschto, "Insurance beyond digital: The rise of ecosystems and platforms", https://www.mckinsey.com/industries/financialservices/our-insights/insurance-beyond-digital-therise-of-ecosystems-and-platforms\#, 2018, accessed $01 / 06 / 2021$

[5] Evans, P. and A. Gawer, "The Rise of the Platform Enterprise: A Global Survey", http://epubs.surrey.ac.uk/id/eprint/811201, 2016, accessed 10/06/2021.

[6] Schenker, J.L., "'The Platform Economy"", https://innovator.news/the-platform-economy3c09439b56, 2019, accessed 29/05/2021.

[7] Atasoy, B., F. Schulte, and A. Steenkamp, "PlatformBased Collaborative Routing using Dynamic Prices as Incentives", Transportation Research Record: Journal of the Transportation Research Board, 2674(10), 2020, pp. 670-679.

[8] Gruchmann, T., N. Pratt, J. Eiten, and A. Melkonyan, "4PL Digital Business Models in Sea Freight Logistics: The Case of FreightHub", Logistics, 4(2), 2020, p. 10.

[9] Soto Setzke, D., M. Böhm, and H. Krcmar, "Platform Openness: A Systematic Literature Review and Avenues for Future Research", WI 2017 Proceedings, 2017.

[10] Parker, G., M.W. van Alstyne, and X. Jiang, "Platform Ecosystems: How Developers Invert the Firm", SSRN Electronic Journal, 2016.

[11] Karhu, K., R. Gustafsson, and K. Lyytinen, "Exploiting and Defending Open Digital Platforms with Boundary Resources: Android's Five Platform Forks", Information Systems Research, 29(2), 2018 , pp. 479-497.

[12] Stummer, C., D. Kundisch, and R. Decker, "Platform Launch Strategies", Business \& Information Systems Engineering, 60(2), 2018, pp. 167-173.

[13] Eisenmann, T.R., "Managing Proprietary and Shared Platforms", California Management Review, 50(4), 2008, pp. 31-53.

[14] Schoder, D., Schlagwein, D. ,Fischbach, K., "Open Resource-Based View (ORBV): A Theory of Resource Openness", ICIS 2019 Proceedings, 2019.

[15] Saadatmand, F., R. Lindgren, and U. Schultze, "Configurations of platform organizations: Implications for complementor engagement", Research Policy, 48(8), 2019, p. 103770.
[16] Schreieck, M. and M. Wiesche, "HOW ESTABLISHED COMPANIES LEVERAGE IT PLATFORMS FOR VALUE CO-CREATION INSIGHTS FROM BANKING", ECIS 2017 Proceedings, 2017.

[17] Möller, F., H. Bauhaus, C. Hoffmann, C. Niess, and B. Otto, "Archetypes of Digital Business Models in Logistics Start-Ups", in Proceedings of the 27th European Conference on Information Systems. 2019: Uppsala, Stockholm.

[18] Möller, F., M. Stachon, C. Hoffmann, H. Bauhaus, and B. Otto, "Data-driven Business Models in Logistics: A Taxonomy of Optimization and Visibility Services", Hawaii International Conference on System Sciences. 2020: Hawaii.

[19] Nickerson, R.C., U. Varshney, and J. Muntermann, "A Method for Taxonomy Development and its Application in Information Systems", European Journal of Information Systems, 22(3), 2013, pp. 336359.

[20] Lambert, S., "Do We Need a "Real" Taxonomy of eBusiness Models?", Flinders University - School of Commerce Research Paper Series(06-6), 2006.

[21] Tiwana, A., Platform ecosystems: Aligning architecture, governance, and strategy, Elsevier/MK Morgan Kaufmann, Amsterdam, 2014.

[22] Asadullah, A., F. Isam, and A. Kankanhalli, "Digital Platforms: A Review and Future Directions", 2018.

[23] Gawer, A. and M.A. Cusumano, "Industry Platforms and Ecosystem Innovation", Journal of Product Innovation Management, 31(3), 2014, pp. 417-433.

[24] Schreieck, M., M. Wiesche, and H. Krcmar, "Design and Governance of Ecosystems - Key Concepts and Future Research", 2016.

[25] King, S.P., "Two-Sided Markets", Australian Economic Review, 46(2), 2013, pp. 247-258.

[26] Tiwana, A., B. Konsynski, and A.A. Bush, "Platform Evolution: Coevolution of Platform Architecture, Governance, and Environmental Dynamics", Information Systems Research, 21(4), 2010, pp. 675687.

[27] Reuver, M. de, C. Sørensen, and R.C. Basole, "The Digital Platform: A Research Agenda", Journal of Information Technology, 33(2), 2017, pp. 124-135.

[28] Baldwin, C.Y. and C.J. Woodard, "The Architecture of Platforms: A Unified View", SSRN Electronic Journal, 2008.

[29] Economides, N. and E. Katsamakas, "Two-Sided Competition of Proprietary vs. Open Source Technology Platforms and the Implications for the Software Industry", Management Science, 52(7), 2006, pp. 1057-1071.

[30] Katz, M.L. and C. Shapiro, "Systems Competition and Network Effects", Journal of Economic Perspectives, 8(2), 1994, pp. 93-115.

[31] Gawer, A., "Digital platforms' boundaries: The interplay of firm scope, platform sides, and digital interfaces", Long Range Planning, 2020, p. 102045.

[32] Hagiu, A. and J. Wright, "Multi-sided platforms", International Journal of Industrial Organization, 43, 2015, pp. 162-174. 
[33] Osterwalder, A., Y. Pigneur, and C.L. Tucci, "Clarifying Business Models: Origins, Present, and Future of the Concept", Communications of the Association for Information Systems, 16, 2005.

[34] Osterwalder, A. and Y. Pigneur, Business model generation: A handbook for visionaries, game changers, and challengers, Wiley, Hoboken, NJ, 2010.

[35] Morris, M., M. Schindehutte, and J. Allen, "The Entrepreneur's Business Model: Toward a Unified Perspective", Journal of Business Research, 58(6), 2005, pp. 726-735.

[36] Bock, M. and M. Wiener, "Towards a Taxonomy of Digital Business Models - Conceptual Dimensions and Empirical Illustrations", in Proceedings of the 38th International Conference on Information Systems. 2017: Seoul.

[37] Zhao, Y., S. von Delft, A. Morgan-Thomas, and T. Buck, "The evolution of platform business models: Exploring competitive battles in the world of platforms", Long Range Planning, 53(4), 2020, p. 101892.

[38] Staub, N., K. Haki, S. Aier, and R. Winter, "Taxonomy of Digital Platforms: A Business Model Perspective", in Proceedings of the 54th Hawaii International Conference on System Sciences, Hawaii: USA. 2021.

[39] Täuscher, K. and S.M. Laudien, "Understanding platform business models: A mixed methods study of marketplaces", European Management Journal, 36(3), 2018, pp. 319-329.

[40] Saebi, T. and N.J. Foss, "Business models for open innovation: Matching heterogeneous open innovation strategies with business model dimensions", European Management Journal, 33(3), 2015, pp. 201-213.

[41] Sharma, S., V. Sugumaran, and B. Rajagopalan, "A framework for creating Hybrid open-source software communities", Information Systems Journal, 12(1), 2002, pp. 7-25.

[42] Fitzgerald, B., "The Transformation of Open Source Software", MIS Quarterly, 30(3), 2006, pp. 587-598.

[43] Abendroth, J., L. Riefle, and C. Benz, "Opening the Black Box of Digital B2B Co-Creation Platforms: A Taxonomy", in Wirtschaftsinformatik 2021 Proceedings. 2021.

[44] Webster, J. and R.T. Watson, "Analyzing the Past to Prepare for the Future: Writing a Literature Review", MIS Quarterly, 26(2), 2002, pp. xiii-xxiii.

[45] Vom Brocke, J., A. Simons, K. Riemer, B. Niehaves, R. Plattfaut, and A. Cleven, "Standing on the Shoulders of Giants: Challenges and Recommendations of Literature Search in Information Systems Research", Communications of the Association for Information Systems, 37(1), 2015, pp. 205-224.

[46] https://angel.co/, accessed 10/06/2021.

[47] https://sourceforge.net/, accessed 10/06/2021.

[48] https://www.capterra.com/, accessed 10/06/2021.

[49] Bailey, K.D., Typologies and Taxonomies: An Introduction to Classification Techniques, SAGE Publications, Thousand Oaks, USA, London, UK, New Dehli, India, 1994.
[50] Szopinski, D., T. Schoormann, and D. Kundisch, "Because your taxonomy is worth it: Towards a framework for taxonomy evaluation", in Proceedings of the 27th European Conference on Information Systems. 2019: Uppsala, Stockholm.

[51] Gerber, A., R. Baskerville, and A. van der Merwe, "A taxonomy of classification approaches in IS research", in Proceedings of the 23rd Americas Conference on Information Systems. 2017: Boston.

[52] Al-Debei, M.M., R. El-Haddadeh, and D. Avison, "Defining the Business Model in the New World of Digital Business", in Proceedings of the Fourteenth Americas Conference on Information Systems. 2008: Toronto: Canada.

[53] Teece, D.J., "Business Models, Business Strategy and Innovation", Long Range Planning, 43(2-3), 2010, pp. 172-194.

[54] van der Valk, H., H. Haße, F. Möller, M. Arbter, J.-L. Henning, and B. Otto, "A Taxonomy of Digital Twins", in Proceedings of the 2020 Americas Conference on Information Systems. 2020: Salt Lake City.

[55] Ritchey, T., "General morphological analysis as a basic scientific modelling method", Technological Forecasting and Social Change, 126, 2018, pp. 81-91.

[56] Rushton, A., P. Croucher, and P. Baker, The handbook of logistics and distribution management:

Understanding the supply chain, 5th edn., Kogan Page, London, 2014.

[57] Chesbrough, H.W. and M.M. Appleyard, "Open Innovation and Strategy", California Management Review, 50(1), 2007, pp. 57-76.

[58] Amrollahi, A., S. Najafikhah, J. Morton, and H. Sarooghi, "DOES OPENING STRATEGY IN ORGANIZATIONS LEAD TO EFFECTIVENESS AND SUCCESS?", in ECIS 2017 Proceedings. 2017.

[59] Yun, J.J., D. Won, K. Park, J. Yang, and X. Zhao, "Growth of a platform business model as an entrepreneurial ecosystem and its effects on regional development", European Planning Studies, 25(5), 2017, pp. 805-826. 